\title{
HABITACIONES CON VISTAS. PULSIÓN ESCÓPICA A TRAVÉS DE LA VENTANA
}

\author{
Emilio CACHORRo FernándeZ \\ Universidad de Granada
}

La ventana, elemento fundamental en arquitectura, también constituye un motivo de especial atención en otras disciplinas, especialmente en pintura, lo que hace interesante explorar las principales ideas o significados que subyacen en la amplia diversidad de formas de mirar a su través, mostrando una gran riqueza interpretativa a nivel internacional con reflejo en el arte español. Este hecho invita a recorrer una selección de sus más destacados episodios pictóricos, mediante los que se ejemplifican distintos sentimientos y sensaciones, no mutuamente excluyentes, revelando poderosas razones por las que la simbología de una simple abertura en la fachada de un edificio despierta fascinación en numerosos artistas y protagoniza una parte importante de sus obras.

Palabras clave: Ventana; Mirada; Relación interior-exterior; Pintura; Arquitectura; Literatura.

\section{ROOMS WITH A VIEW. SCOPIC PULSION THROUGH THE WINDOW}

The window, essential element in architecture, is also a matter of particular attention in other media, particularly painting. Therefore it is interesting to explore the main ideas or meanings underlying the wide diversity of ways of looking through it, demonstrating a wealth of interpretation on an international level, with reflection as well in Spanish art. This circumstance invites the analysis of a selection of its most outstanding pictorial episodes, by which different feelings and sensations are illustrated, revealing powerful reasons for why the symbolism of a simple opening on a building facade fascinates many artists and becomes an important part of their creations.

Key words: Window; Looking; Relationship inside-outside; Painting; Architecture; Literature.

Entre otros, Julio Cortázar, en boca de uno de sus entrañables personajes - Traveler-, decía que "Las ventanas son los ojos de la ciudad", en línea con el antropólogo Gilbert Durand cuando habla de que "...espontáneamente el niño reconoce en las ventanas los ojos de la casa"; en ambos casos, destacando la importancia de un elemento arquitectónico, aparentemente simple, pero con un cometido esencial a nivel perceptivo y sensorial, que conecta los dos ámbitos básicos de la concepción espacial, exterior e interior, con todas sus múltiples implicaciones.

\footnotetext{
${ }^{1}$ Cortázar, 1963: 41. Durand, 1982: 231.
} 
Pese a ser determinante a la hora de concebir una obra, estamos ante un tema poco tratado por la historiografía. Debido a ello, evocando el título de la novela $A$ room with a view (1908) de E. M. Foster ${ }^{2}$, se pretende investigar la repercusión del hecho de mirar por una ventana, característico no solo en arquitectura sino también en artes plásticas e, incluso, literatura, y que sobrepasa los límites de un acto meramente físico. Souto de Moura ha señalado recientemente que, si se piensa por un momento en la historia de la ventana, es posible comprobar que no sólo se trata de la evolución de un lenguaje o de una moda, sino también del propósito de crear sensaciones intensas a partir de su diseño ${ }^{3}$, mientras que Peter Zumthor escribe, a propósito de Edward Hopper, sobre el enorme orgullo que siente, como arquitecto, de poder concebir cosas parecidas en cada obra, lo que guía cada uno de sus proyectos en los que constantemente se pregunta: ¿qué quiero ver yo cuando estoy dentro? ¿qué quiero que vean los otros de mí? ${ }^{4}$.

Su reiteración como argumento inspirador de la producción artística da pie a profundizar por esta vía en su germen ideológico, mediante la lectura transversal que aporta el análisis de una amplia muestra de trabajos representativos de diferentes épocas, estilos y autores, de fuera y dentro de nuestras fronteras, seleccionados a partir de su indiscutible atención por la ventana. Un objetivo asistido del examen de textos o pasajes literarios también referidos a esta misma materia, con la pretensión de favorecer el esclarecimiento de cualquier posible carga simbólica. Los resultados se han agrupado según conceptos, de acuerdo al grado de relevancia apreciado en cada una de las obras, con cierto orden cronológico para su mejor análisis, huyendo de una excesiva individualización que dificulte la visión de conjunto pero sin afán de elaborar un inventario que, además, resultaría del todo inabarcable.

\section{Raíces instrumentales}

Con la formación del pensamiento renacentista en el siglo XV, se comenzó a identificar la actividad pictórica con la idea de «ventana». Se pretendía que la pintura adoptara el principio de visión del mundo, según el cual, es posible representarlo por medio del recorte que la mirada determina como encuadre preciso, permitiendo ver un segmento escogido o microcosmos. Leon Battista Alberti pensaba que la pintura debía producir una imagen que plasmara la realidad visible como si el observador estuviera asomado a una ventana; creía que el arte es como una ventana abierta por la que se percibe la historia que se quiere expresar ${ }^{5}$. Un criterio compartido por Leonardo de Vinci, para quien la pintura de un cuadro se ha de considerar vista por una de estas aberturas ${ }^{6}$.

El medio que mejor lo facilitó fue la perspectiva lineal -término de raíz latina que significa «óptica», mirar a través-, gracias a su condición de estructura centralizada que manifiesta una clara dependencia de sus bordes. Se dota así al dibujo del carácter de una sólida construcción que, en muchos casos, tendería a evocar un mundo ideal más que ceñirse a la realidad, sin renunciar a un adecuado aporte simbólico? .

El género de una superficie enmarcada por otra, también conocido como «ventana dentro de la ventana» o, en definitiva, «cuadro dentro del cuadro», donde incluso llegan a escenificarse atmósferas bien distintas, empezaría a ser objeto de experimentación reiterada a partir de entonces. La pintura flamenca sería una de las más prolijas en este sentido; dos de sus principales pioneros fueron Jan van Eyck y Rogier van der Weyden, con obras como La Virgen y el Canciller Rolin

\footnotetext{
${ }^{2}$ Véase Forster, 2005 -adaptada a versión cinematográfica homónina bajo la dirección de James Ivory (1985).

${ }^{3}$ Véase Nufrio, 2008: p. 68.

${ }^{4}$ Zumthor, 2006: 49.

5 Véase Leonardo de Vinci; Alberti, "Los tres libros de la pintura por Leon Bautista Alberti” (libro I), 1980: 215.

${ }^{6}$ Véase Leonardo de Vinci; Alberti, "El Tratado de la Pintura de Leonardo de Vinci” (Sección LIX), 1980: 25.

7 Véase Panofsky, 1999.
} 
(h. 1430-34) y San Lucas dibujando a la Virgen (h. 1435-40), respectivamente, de concepción similar en tanto que ambas se desarrollan frente a un mirador, con vistas a un paisaje urbano y fluvial de fondo que les proporciona una gran sensación de profundidad, acentuada más aún mediante el dibujo fugado de otro tipo de elementos -solería, cierres laterales...

Además de la perspectiva, en el alto Renacimiento italiano se habilitó otro recurso destinado a superar la planitud del lienzo, a potenciar la tercera dimensión: el empleo de «espejos», incorporados plenamente en la composición como objetos determinantes -y no meros utensilios-, que nos descubren lo oculto de similar modo que lo hace una ventana, para poder mirar al otro lado del plano donde se halla. El ejemplo de Tiziano, con su Venus ante el espejo (1555), desplegaría gran influencia en pintores como Rubens, Velázquez... Un fondo que igualmente se alcanza mediante otro tipo de reflejos, en el agua, en piezas metálicas, etc., cuyo fundamento puede ser entendible como antecedente lejano del Cubismo en tanto que agrupa, en una misma representación, diversos puntos de vista o múltiples frontalidades.

\section{Dimensión Semiótica}

\section{Misterio}

Anticipando lo anterior, uno de los precusores en romper con las limitaciones del arte medieval en el siglo XIV, para ensayar todavía de manera primaria con el espacio, fue Giotto, dando muestras de su interés por incorporar arcadas, puertas y ventanas en sus imágenes, fundamentalmente religiosas, mediante las que se presiente un interrogante existencial. Giorgio De Chirico, analizando la pintura primitiva, nos apunta cómo "la arquitectura completa a la naturaleza", haciendo que un trozo de cielo limitado por el contorno de una abertura se convierta en un segundo drama dentro de la obra, añadido al que ya proponen las figuras, acerca del que surgen preguntas turbadoras: “¿Qué habrá más allá? ¿Acaso domina ese cielo un mar desierto, o una ciudad populosa? ¿O se extiende sobre la gran naturaleza libre e inquieta, los montes selváticos, los oscuros valles, las llanuras surcadas por ríos?"».

Continuando la reflexión, esta vez referida al Cinquecento, el mismo autor nos insiste sobre la bondad de dicho aspecto por medio de cuadros de Tintoretto como Retrato de un hombre con armadura de adornos dorados (h. 1555-1556) y Retrato de Vincenzo Zeno (h. 1565), donde la presencia arquitectónica imprime un significativo valor metafísico, situando ilustres personajes junto a vanos rectangulares, con cielo y mar de fondo, dotados de un profundo lirismo, lo que induce a la mente a pensar por cuanto proporciona un notable factor sorpresa y de afán por el descubrimiento, suscitando la duda de qué puede haber tras la pared ${ }^{9}$.

Los pintores holandeses del siglo XVII siguieron avanzando en esta línea. En particular, Johannes Vermeer llevó a cabo numerosos y apacibles interiores con mujeres ensimismadas, entregadas al desarrollo de diferentes actividades, generalmente próximas o frente a una cristalera, entre los que destaca Brieflezend meisje bij het venster (Muchacha leyendo una carta en una ventana abierta, h. 1659) (fig. 1). En sus trabajos, los huecos se disponen en un plano casi perpendicular al definido por la propia tela, de modo que el espectador, al que se le niega la posibilidad de asomarse a ellos, excita su curiosidad al ver cómo los personajes participan de algo que resulta desconocido, enigmático, igual de indescifrable que su reservada personalidad, lo que redunda en una mayor protección de su privacidad o intimidad ${ }^{10}$.

\footnotetext{
${ }^{8}$ De Chirico, 1990: 66-68.

9 De Chirico, 1990: 72-73.

${ }^{10}$ Con relación a este autor, entre otros trabajos, véase Bozal, 2002.
}

Arch. esp. arte, LXXXVIII, 350, ABRIL-JUNIO 2015, 157-172

ISSN: 0004-0428, eISSN: 1988-8511, doi: 10.3989/aearte.2015.10 


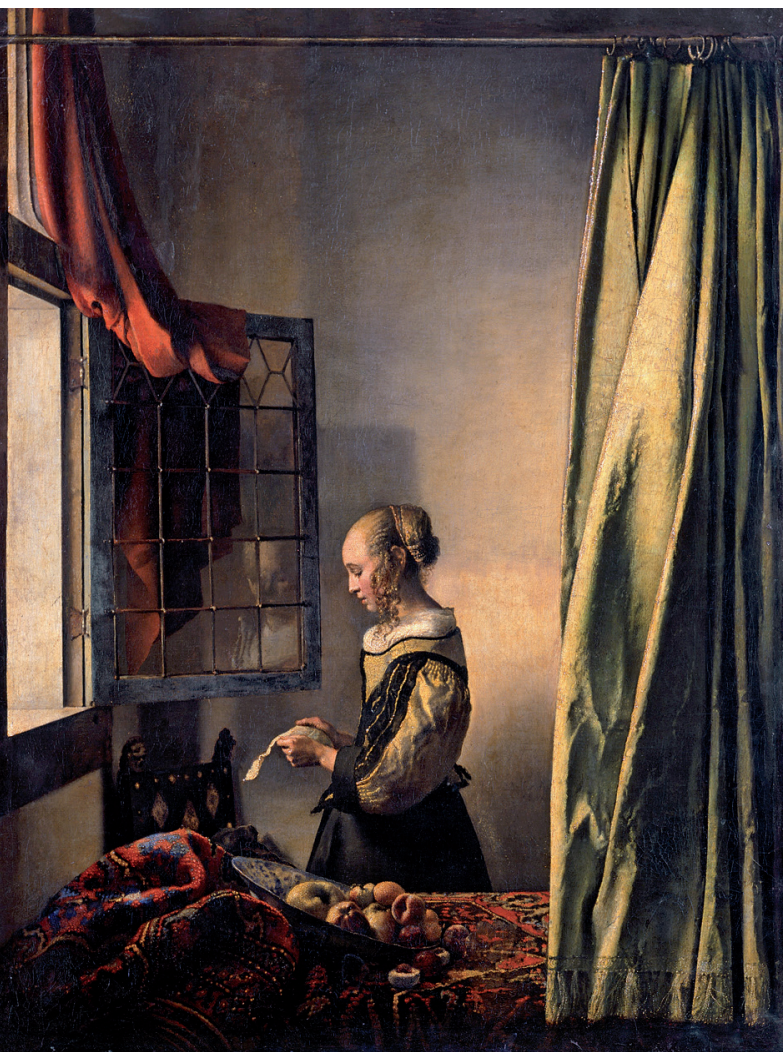

Fig. 1. Johannes Vermeer: Brieflezend meisje bij het venster (Muchacha leyendo una carta en una ventana abierta) -óleo sobre lienzo, 83 x 64,5 cm- (h. 1659). Gemäldegalerie Alte Meister, Staatliche

Kunstsammlungen Dresden. 1336. Fotografía: Elke Estel/Hans-Peter Klut.

Esta circunstancia recuerda las reflexiones de Charles Baudelaire en las que aborda lo sugerente que puede llegar a ser un hueco, incluso en el caso de que no se pueda ver por él, al menos con claridad, ya que siempre acciona los resortes mentales y sentimentales del ser humano. Él francés pensaba, intercambiando el punto de vista - de lo externo proyectado hacia lo interno-, que: "El que mira desde afuera por una ventana abierta no ve nunca tantas cosas como el que mira una ventana cerrada. No hay objeto más profundo, más misterioso, más fecundo, más tenebroso, más deslumbrante, que una ventana iluminada con una vela. Lo que puede verse al sol es siempre menos interesante que lo que sucede tras un cristal. En ese agujero negro o luminoso vive la vida, sueña la vida, sufre la vida" $"$. De este modo, según Baudelaire, cuando se divisa a una persona entre un mar de tejados, con poco más que advertir su rostro, sus gestos y su vestimenta, es posible reconstruir toda su historia o, incluso, hasta su leyenda, sin importar que pueda o no ser verdad.

Un argumento que, recientemente, ha sido manejado por Amos Oz en su discurso La mujer de la ventana ${ }^{12}$, en el que se refiere a la capacidad incisiva que tiene la literatura -y que resulta perfectamente extrapolable a todas las artes-, en cuanto que permite llegar más lejos de lo puramente visible y superficial. El escritor israelí, acudiendo al ejemplo del típico turista, nos habla de que, cuando visita una ciudad, puede tener la oportunidad de recobrar el aliento en algún encantador rincón, y contemplar una bella casa, donde se descubra una mujer en su fachada, pero luego dará la vuelta y continuará su camino; sin embargo, si adquiere la ocupación de lector, no solo observará a esa dama, sino que podrá estar con ella, acompañándola en su casa, buceando en las entrañas de su corazón y su cabeza.

\section{Libertad}

La influencia holandesa debió ser causa de que, en nuestro país, Bartolomé Esteban Murillo realizara Dos mujeres en una ventana -también conocido como Las gallegas - (h. 1655-1660)

\footnotetext{
${ }^{11}$ Baudelaire, "Las ventanas", 2009: 165-166.

12 Pronunciado con motivo de la entrega del Premio Príncipe de Asturias de las Letras 2007, con el que fue galardonado.
} 
(fig. 2), en el que dos chicas jóvenes, presuntamente pícaras, aparecen asomadas a la calle, una medio tapada con su chal y otra a cara descubierta; son las dos alternativas que permite la ventana: mirar dejándose ver o mirar sin ser visto - con la ayuda de algún velo dispuesto para ello-. Un cuadro aparentemente inspirado en la tradición de imágenes moralizantes neerlandesas que mostraban chicas jóvenes acompañadas de sus alcahuetas, lo que suscitaría continuo interés a lo largo de diferentes épocas, como demostró, más de un siglo después, Francisco de Goya a través de su Maja y celestina al balcón (h. 1808-1812).

Como piensa Carmen Martín Gaite, la ventana representa el símbolo de lo fronterizo y, por tanto, es sinónimo de redención, lo que hace indispensable que cada ser humano recurra a la suya propia, real o ficticia, para no creerse preso y marginado. A su juicio, la ventana es el mejor aliado que posee la mujer para soñar, sin salir al exterior, la vida que discurre fuera, dejando vagar su fantasía en los ratos de tregua que conceden las tareas domésticas, a las que se enfrenta sin expectativas de un mínimo reporte de alegría o satisfacción; es un puente construido entre las orillas de lo conocido y

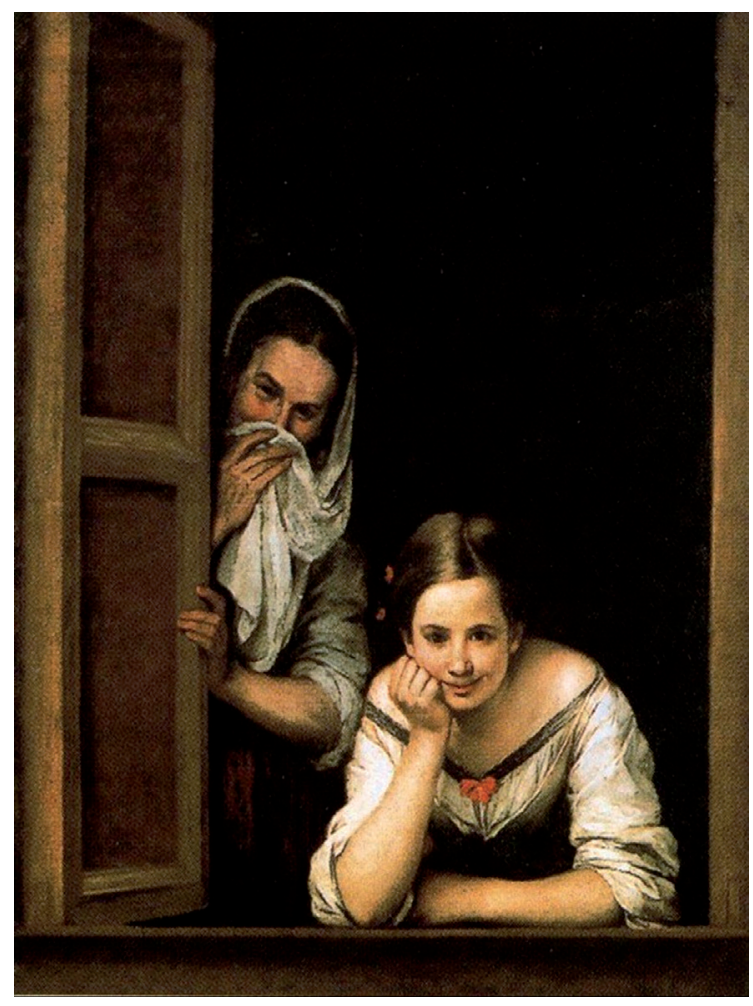

Fig. 2. Bartolomé Esteban Murillo: Dos mujeres en una ventana -óleo sobre lienzo, 125,1 x 104,5 cm(h. 1655-1660). National Gallery of Art, Washington. lo desconocido, la única brecha por donde echar a volar en busca de una nueva existencia, de otra vida que le haga sentirse realizada. La ventana se torna así en eficaz sistema de evasión del confinamiento que produce el hogar, se entiende como atalaya desde donde huir del encierro infligido por una morada claustrofóbica, lo que le lleva a desesperar amargamente pregonando: "Abrid ya las ventanas. / Adentro las ventiscas / y el aire se renueve"13.

Hay que considerar a los autores del Siglo de Oro entre los inspiradores del adjetivo «ventanera» ${ }^{14}$-frecuentemente asociado con «liviana»-, recuperado en el léxico de Martín Gaite, cuyo empleo en femenino era signo de censura en aquella época, para reprobar que algunas muchachas levantaran la vista -habitualmente a escondidas- por encima de la parcela física individual, bastante acotada, que un sector de la sociedad les asignaba. No obstante, será Rosalía de Castro quien se erija en uno de los máximos referentes de la salmantina, por sus constantes alusiones a la ventana

${ }^{13}$ Martín Gaite, 2001: 25. Sobre el alcance que entraña la ventana en el ideario de esta autora, resulta de interés Martín Gaite, 1958; 1987; así como los comentarios vertidos en ToRre FicA, 2001-2002.

${ }^{14}$ Resulta cuando menos curiosa la distinta acepción que otorga el diccionario de la RAE al término «ventanero/ra» según se emplee uno u otro género, atribuyendo el femenino para mujeres ociosas, muy aficionadas a asomarse a la ventana para ver y ser vistas, mientras que el masculino se asocia con hombres que miran con descaro a las ventanas en que hay mujeres; es decir, el femenino se utiliza en dirección dentro-fuera mientras que el masculino adquiere el sentido contrario.

Arch. esp. arte, LXXXVIII, 350, ABRIL-JUNIO 2015, 157-172

ISSN: 0004-0428, eISSN: 1988-8511, doi: 10.3989/aearte.2015.10 
como herramienta con la que romper cadenas y configurar una vía de escape, hasta el punto de que sus últimas palabras pronunciadas en vida fueron: "abre esa ventana, que quiero ver el mar"15.

Un pensamiento igualmente recogido en la conmovedora poesía de Constantino Cavafis cuando, en los primeros versos de Las ventanas (1903), escribe: "En estas oscuras piezas, donde paso / días agobiantes, voy y vuelvo arriba abajo / para hallar las ventanas. Cuando se abra / una ventana habrá un consuelo..."16; y en la narrativa de García Lorca, según se desprende de La Casa de Bernarda Alba (1936), donde este tipo de huecos aparece como cauce principal de conexión con el mundo exterior, como forma de paliar mínimamente la severa reclusión a que están sometidas sus jóvenes protagonistas ${ }^{17}$.

\section{Trascendencia}

Será la pintura alemana -junto a la danesa, francesa y rusa- del siglo XIX la que, sobre todo, adopte la ventana como tema fundamenta $1^{18}$. Georg F. Kersting inmortalizó a varios de sus compañeros ejercitando su arte; en Caspar David Friedrich in seinem Atelier (Caspar David Friedrich en su estudio, 1812), la luz proviene de un hueco que recorta un simple trozo de cielo, quedando tapado el entorno por unos paneles colocados en la parte inferior. Estos reguladores de luz eran indispensables para el trabajo de Friedrich, tal como se aprecia en Frau am fenster (Mujer en la ventana, 1822), donde aparece su esposa Caroline Bommer -de espaldas- en el que fuera su taller, cuya figura destaca por la austeridad de la habitación, observando el río Elba gracias a la apertura de uno de dichos cierres; las líneas del suelo acentúan la aproximación hacia el plano de la pared y el exterior. La simbología es clara: el sombrío interior representa el mundo terrenal de los vivos, mientras que la ventana es el ámbito que lo relaciona con el mundo celestial que la mujer contempla -los barcos que se insinúan reflejan dicho tránsito--

Una idea que se puede asociar con el pensamiento apuntado, hace tan solo unas décadas, por Hans van der Laan, quien entendía, a partir de su doble condición de arquitecto y monje benedictino, que los edificios deben actuar como intercesores entre tierra y cielo; la casa es el medio por el que se consuma la reconciliación del hombre con la naturaleza, gracias a su vocación de compartimentar espacios con muros y relacionarlos con puertas y ventanas, por donde los interiores se inundan de luz natural a la vez que dialogan con un contexto que pide ser contemplado, en especial, buscando una conexión visual con la llamativa vegetación de jardines y huertas ${ }^{19}$.

Otros pintores románticos decimonónicos, discípulos y amigos del propio Friedrich, también fueron atraídos por el género denominado Fensterbild. Tal es el caso de Johann Christian Claussen Dahl, autor de Blick aus einem fenster auf Schloss Pillnitz (Vista desde una ventana del Palacio de Pillnitz, 1824), donde igualmente exhibe una imagen cargada de componentes metafóricos. Con

${ }^{15}$ Son palabras que dirigió a su hija Alejandra (Padrón, 15 de julio de 1885), según se describe en González Besada, 1916: 73. Y es que, según se relata en Filgueira Valverde, 1974: 42, solía escribir junto a la ventana, lo que inspiró muchos de sus poemas: “...desde mis ventanas veo / el templo que quise tanto..." (de "Orillas del Sar" I); "Yo desde mi ventana, / que azotan los airados elementos, / regocijada y pensativa escucho / el discorde concierto / simpático a mi alma..." (de "Cenicientas las aguas, los desnudos"); "Fue ayer y es hoy y siempre: / al abrir mi ventana / veo en Oriente amanecer la aurora, / después hundirse el sol en lontananza" (de "Una cuerda tirante guarda mi seno") -véase Rosalía de Castro, 1993.

16 Véase Cavafis, 2000

${ }^{17}$ Recuérdese la relación que entablan dos de las hijas de Bernarda (Angustias y Adela) con Pepe 'El Romano' por medio de encuentros nocturnos a través de una ventana.

${ }^{18}$ Véase Rewald, 2011. Asimismo, ciñiendo este mismo contenido al país germano, se puede consultar Eitner, 1955. Forssman, 1966, Schmoll, 1967; 1970

19 Véase Van der Laan, 1989. 
más intensidad si cabe que su maestro, empleó la dualidad cromática de planos para reforzar la idea de separación entre dos mundos: por un lado, la oscuridad de nuestro presente inmediato $\mathrm{y}$, por otro, la claridad del futuro lejano.

Es bien sabida la correlación que se hace, desde la mitología antigua, de la luz solar con la manifestación de Dios, lo que otorga a la ventana un papel esencial en la medida que posibilita gozar de dicha irradiación $y$, por tanto, de un contacto virtual con el ser superior. Pero no es menos importante el rol que asume, con gran contenido alegórico, como 'túnel' por el que los humanos invocan a su divinidad y, en sentido inverso, por el que ésta reclama la espiritualidad del hombre. Este supuesto es el que describe Lope de Vega, dentro de sus célebres Rimas sacras (1614), escritas el mismo año de su ordenación como sacerdote, y donde, con voz coloquial pero íntima, expresa: “¡Cuántas veces el Ángel me decía: / Alma, asómate agora a la ventana, / verás con cuánto amor llamar porfía!"20.

\section{Compromiso}

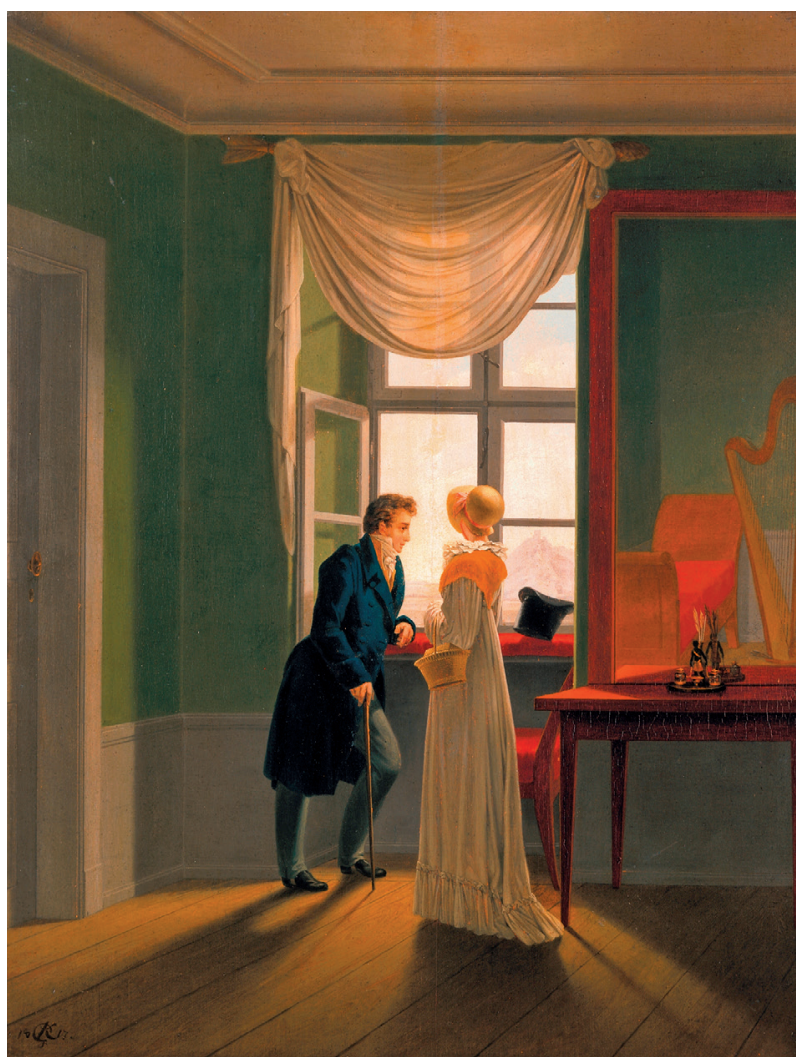

Fig. 3. Georg F. Kersting: Pareja en la ventana -óleo sobre lienzo, 47 x 36,5 cm- (1817). Museum Georg Schäfer, Schweinfurt.

La reproducción de una escena muy similar a la reflejada por Kersting en Paar am fenster (Pareja en la ventana, 1817) (fig. 3) servirá para que, con un objetivo bien distinto, Honoré Daumier despliegue su ingeniosa y mordaz sátira por medio de la litografía Les gentilshommes campagnards (Burgueses en el campo, 1864), ridiculizando a los esnobs parisinos. Así, junto a la caricatura de un matrimonio supuestamente de clase media-alta, asomado al balcón de su casa de campo, acompañó la probable conversación que mantendrían ambos a la llegada del otoño - al mismo tiempo que el marido lanza un bostezo-: "MADAME: Nous voici arrivés au quinze novembre, le temps commence à se gâter, je crois qu'íl faudra songer bientôt à rentrer à Paris... Monsieur: C'est aussi mon ô...ô...ô....pinion!..." ${ }^{\text {,2 }}$, ironizando sobre las ataduras y molestias que es capaz de soportar la gente acomodada, de forma voluntaria, por tal de aparentar y presumir de un determinado estatus -incluso un profundo aburrimiento por verse 'obligados a disfrutar' de su villa de recreo a pesar de las permanentes lluvias.

\footnotetext{
${ }^{20}$ Tercer párrafo del soneto “¿Qué tengo yo que mi amistad procuras?”; una de las ediciones recientes en la que se incluye es Haro Tecglen, 2000: 94.

${ }^{21}$ Tr. propia: "Señora: Estamos a 15 de noviembre, el tiempo comienza a empeorar, creo que debemos considerar la posibilidad de volver pronto a París. Señor: ¡También es mi o...o...o...pinión!...”.
}

Arch. esp. arte, LXXXVIII, 350, ABRIL-JUNIO 2015, 157-172

ISSN: 0004-0428, eISSN: 1988-8511, doi: 10.3989/aearte.2015.10 
No lejos de la capital francesa y con ocasión del desarrollo industrial, Vincent van Gogh se haría eco de las nuevas condiciones sociolaborales, denunciando la situación de los trabajadores holandeses a través del Weber vor offenem fenster mit blick auf den Turm von Nuenem (Tejedor delante de ventana abierta con vistas a la torre de Nuenen, 1884), donde la penumbra se asocia a un detestado maquinismo emergente -representado por la figura de un telar que invade el interior de un taller artesano-, en contraste con la decadente pero añorada actividad campesina que se percibe al fondo, en el exterior, caracterizada por una extraordinaria luminosidad. El hueco vuelve a ser una frontera difícil de traspasar, en este caso, deslindando lo que podíamos entender por realidad vivida y realidad deseada, presente y pasado.

Una crítica social que, acudiendo de nuevo al ámbito literario, identificó sólidamente el pensamiento de Baudelaire, quien consideraba que la ciudad moderna constituye el escenario de un encuentro vivo -e inevitable- de constantes miradas, lo que no supone, en numerosas ocasiones, una victoria contra la segregación y la marginación. Hecho que se recoge a la perfección en su texto Los ojos de los pobres ${ }^{22}$, donde trasciende la barrera social que puede suponer el límite físico de una puerta, de una ventana o, simplemente, el pequeño espacio que media entre dos personas pero que, por desgracia, termina separando dos mundos opuestos con muy distinta fortuna ${ }^{23}$.

\section{Hábitat}

La implantación generalizada del ferrocarril ofreció la posibilidad, más allá de su función como medio de transporte, de disponer de una nueva plataforma desde donde admirar generosas vistas -especialmente del medio rural- a través de los grandes ventanales de sus vagones, muy parecidas a las que perpetuaban los pintores impresionistas. Dichas aberturas hacían sentir a todos los viajeros la condición de paisajistas por cuanto adoptaban forma de marco, según llegó a declarar Jules Claretie ${ }^{24}$; o, alternativamente, la de fotógrafos, en la medida que los trenes se comportaban igual que el objetivo de una cámara: eran auténticos mecanismos y plataformas de «archivisión» que fabricaban, al encuadrarla, una nueva realidad, concediendo al ojo del pasajero la capacidad de fijar imágenes. De este modo, rápidamente prosperaría la idea del 'tren-artista', moviendo incluso a poetas a celebrar las experiencias psicológicas y sensoriales vividas por la experimentación de los panoramas; es el caso de Paul Verlaine cuando nos describe: "Le paysage dans le cadre des portières / Court furieusement, et des plaines entières / Avec de l'eau, des blés, des arbres et du ciel / Vont s'engouffrant parmi le tourbillon cruel / Où tombent les poteaux minces du télégraphe / Dont les fils ont l'allure étrange d'un paraphe"25.

Un efecto muy similar al que, a nivel arquitectónico, produce la fenêtre en longueur (ventana horizontal) corbusieriana, y que condujo a su creador a una seria disputa con Auguste Perret, quien le acusó de forzar los huecos alargándolos de manera indiscriminada, en vez de preferir la portefenêtre (puerta-ventana), no tanto por cuestiones lumínicas y antropomórficas, sino debido al encuadre simultáneo que proporciona de una vista lejana junto a otras más cercanas. El que fuera maestro de Le Corbusier defendía que, mediante huecos erguidos, es como realmente se consigue una visión en perspectiva, al igual que acontece en un cuadro flamenco, donde coexiste un primer plano con otro intermedio a los que se añade un tercero de carácter más general; por el contrario,

${ }^{22}$ Baudelaire, "Los ojos de los pobres ", 2009: 121-124.

${ }^{23}$ Sobre esta materia, véanse Berman, 1991. Calatrava, 1996: 54-62.

24 Véase Robles Tardío, 2008: 23-28.

${ }^{25}$ Tr.: "El paisaje en el marco de las ventanas / corre furiosamente, y llanuras enteras / con su agua, sus trigos, árboles y cielo / van precipitándose en el torbellino cruel / donde caen los postes delgados del telégrafo, / cuyos hilos tienen el aire extraño de una rúbrica" -Verlaine, 1991.

Arch. esp. arte, LXXXVIII, 350, ABRIL-JUNIO 2015, 157-172 ISSN: 0004-0428, eISSN: 1988-8511, doi: 10.3989/aearte.2015.10 
los huecos apaisados solo permiten observar en la media distancia, convirtiendo la percepción en una imagen plana, sin profundidad, que parece flotar en el espacio como una proyección cinematográfica. Perret entendía que la ventana vertical, además de ser fiel a la tradición francesa, constituye la mejor tipología para deleitarse, en toda su magnitud, con el esplendor urbano de origen haussmanniano, algo que la disposición tumbada impide, según su criterio, pues recorta excesivamente la distancia que media entre suelo y techo ${ }^{26}$.

Demostración de ello fue la obra de Gustave Caillebotte, gracias al realismo desplegado en sus famosas escenas del transformado París de Napoleón III, quien refleja la ambientación ciudadana valiéndose de los amplios huecos de las viviendas burguesas, como acontece en Jeune homme à sa fenêtre (Hombre joven en la ventana, 1875) -posando su hermano René en la casa familiar de rue Miromesnil- o en L'Homme au balcon, boulevard Haussmann (Hombre en el balcón, boulevard Haussmann, 1880), donde las siluetas ennegrecidas de sus personajes aparecen al contraluz de los balcones a los que se asoman, cediendo el protagonismo a calles y avenidas que delatan el nacimiento de la efervescente metrópoli moderna.

Sea cual fuera el contexto, han sido muchos los cautivados por una porción de ciudad capturada entre jambas. Henri Matisse nos exhibirá enclaves tan diversos como Tánger, Niza, París... Fenêtre ouverte, Collioure (Ventana abierta, Collioure, 1905), Femme assise, le dos tourné vers la fenêtre ouverte (Mujer sentada, con la espalda vuelta a la ventana abierta, 1922) y tantos otros verán sustituido el ojo pasivo de los impresionistas - que se deja envolver por la naturaleza-por una conducta más selectiva, prendiendo tan solo un fragmento de mundo con el que, además, se pretende mantener la distancia ${ }^{27}$. De manera coetánea, Marc Chagall, con cuadros como Paris par la fenêtre (París a través de la ventana, 1913) (fig. 4), ${ }^{28}$ asumiría el criterio de considerar el umbral como un espacio intermedio, vínculo entre seres humanos y entorno. Incluso Pablo Picasso llegó a convertirlo, entre 1917 y 1920, en uno de los ejes de su obra, para descubrirnos, por ejemplo, aunque de manera distorsionada, las vistas que se disfrutan desde el hotel Ranzini de Barcelona, asomándonos a El paseo de Colón (1917) en un óleo que es preámbulo de su serie de ventanas abiertas, donde el hueco se alza como una estructura que potencia, con su práctica ausencia de colores típica del Cubismo-, la visión del frente marítimo de fondo, al que se le dota de mayor vivacidad ${ }^{29}$.

En situación parecida, con el añadido de un cierto arrepentimiento por no haber disfrutado más de las cosas mundanas, de lo que nos ofrece el día a día -en lugar de perder demasiado tiempo con especulaciones-, resuenan los sentidos versos de Fernando Pessoa: "Chego à janela e vejo a rua com uma nitidez absoluta, / vejo as lojas, vejo os passeios, vejo os carros que passam, / vejo os entes vivos vestidos que se cruzam, / vejo os cães que também existem, / e tudo isto me pesa como uma condenação ao degredo, / e tudo isto é estrangeiro, como tudo"30.

${ }^{26}$ La diatriba entre ambos arquitectos afloró con motivo del Salon d'Automne de la capital gala en 1923 -celebrado del 1 de noviembre al 16 de diciembre-, haciéndose pública a través de las siguientes entrevistas: "M. Auguste Perret nous parle de l'architecture au Salon d'Automne", en Paris Journal, 1 de diciembre de 1923; "Une visite à Le Corbusier-Saugnier", en Paris Journal, 14 de diciembre de 1923; y "Seconde visite à Le Corbusier", en Paris Journal, 28 de diciembre de 1923 (estas últimas suscritas por el periodista Guillaume Baderre). También se puede consultar Dumont, 2002.

${ }^{27}$ Véase Blum, 2010.

${ }^{28}$ Véase Frechuret; Müller; Pacoud-Reme, 2008.

${ }^{29}$ Véase Ocaña, 1999 -es significativo que el primero de los cinco ámbitos de la muestra fue titulado "1917-1920. La ventana: nexo entre la realidad y lo imaginado"-. Los parajes exteriores fueron recurrentes en la etapa de formación del pintor malagueño quien, tras incrementar sus contactos con las vanguardias, evolucionó hacia un mayor interés por los espacios interiores.

${ }^{30}$ Tr.: "Me acerco a la ventana y veo la calle con absoluta claridad, / veo las tiendas, veo las aceras, veo los coches que pasan, / veo a los entes vivos vestidos que se cruzan, / veo a los perros que también existen, / y todo esto me pesa como una condena al destierro, / y todo esto es extranjero, como todo" -de "Tabaquería", incluido en Pessoa, 2009: 316, escrito bajo el seudónimo de Álvaro de Campos--. Con relación a lo anterior y haciendo gala de un sentido alegórico, el poeta lusitano

Arch. esp. arte, LXXXVIII, 350, ABRIL-JUNIO 2015, 157-172

ISSN: 0004-0428, eISSN: 1988-8511, doi: 10.3989/aearte.2015.10 


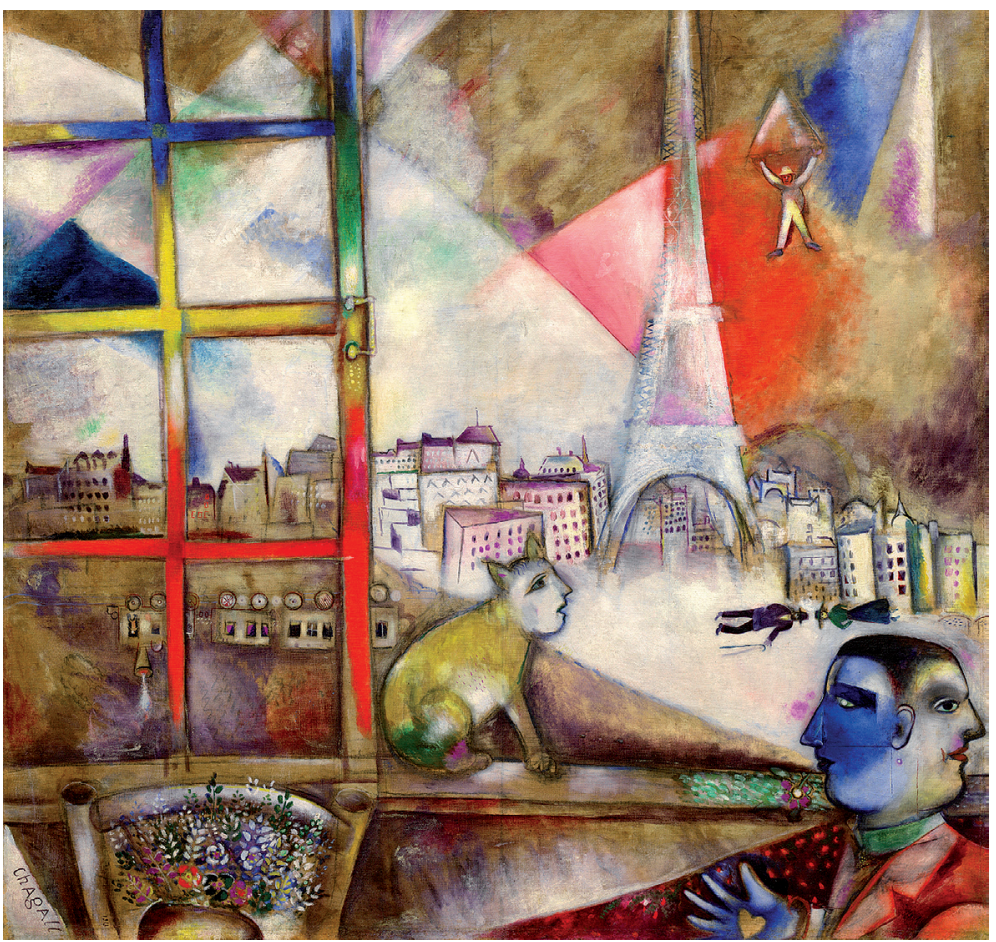

Fig. 4. Marc Chagall:

Paris par la fenêtre (París a través de la ventana) -óleo sobre lienzo, 136 x 141,9 cm- (1913). Solomon R. Guggenheim Museum, Nueva York; Solomon R. Guggenheim Founding Collection, por donación. 37.438.

\section{Extraversión}

Como una herencia clásica recuperada en su etapa formativa de carácter aún realista, Salvador Dalí dibujó Figura en una ventana (1925) (fig. 5), en la que aparece su hermana en una habitación de la casa familiar que el pintor adoptó como estudio, en actitud contemplativa, disfrutando de la relajante vista de la bahía de Cadaqués y del mar Mediterráneo. Un lienzo con gran uniformidad cromática -en tonos azules-, que nos confiere sensación de serenidad, y donde, mediante una sencilla composición, la muchacha retratada parece asomarse al mundo a la par que también se invita a que lo haga el mismo espectador -con estilo completamente opuesto a su posterior versión, de tintes surrealistas, titulada Joven virgen sodomizada por su propia castidad (1954) ${ }^{31}$.

Resulta casi automática la comparación del cuadro de Dalí con el previamente mencionado de Friedrich, así como con algunos otros del mismo contenido; es el caso de Fille au fenêtre (Muchacha en la ventana, 1957) de Balthus, donde el autor vuelve a incitarnos a interactuar con el paisaje enmarcado. En general, se puede observar como, en orden cronológico, las aberturas se van agrandando y la imagen en su conjunto gana luz y color de forma gradual, lo que se puede interpretar como un reflejo de la evolución social acontecida a través de las etapas históricas en

también escribió: "No basta abrir la ventana / para ver los campos y el río. / No es suficiente no ser ciego / para ver los árboles y las flores. / También es necesario no tener ninguna filosofía. / Con filosofía no hay árboles: no hay más que ideas. / Solo hay, como una cueva, cada uno de nosotros. / Hay sólo una ventana cerrada, y todo el mundo fuera; / y un sueño de lo que se podría ver si la ventana se abriese, / que nunca es lo que se ve cuando se abre la ventana" (estrofa única del n 1 de "Poemas inconjuntos (1913-1915)" -firmado con el seudónimo de Alberto Caeiro-, extraído de Pessoa, 2009: 199).

${ }^{31}$ Realizada tras el descontento del artista al conocer la descripción que se hizo de su persona en Dalí, 1949.

Arch. esp. arte, LXXXVIII, 350, ABRIL-JUNIO 2015, 157-172 ISSN: 0004-0428, eISSN: 1988-8511, doi: 10.3989/aearte.2015.10 
las que se inscriben, donde valores tales como dignidad, confianza, optimismo, etc. enraízan en el sentimiento colectivo, sustituyendo al oscurantismo de siglos anteriores.

Hay que recordar que, como apunta Leonardo Benévolo, desde finales del siglo XVI hasta concluir el siglo XVIII fue evolucionando la idea que se tenía de «mundo»y, en consecuencia, cambió el concepto de «infinito»: de límite de aquel, metafísico o religioso, pasó a ser una parte suya, perfectamente explorable a través de la investigación y virtualmente traspasable ${ }^{32}$; algo que trae causa, sin duda, entre otras circunstancias, del desarrollo de una nueva cosmología, que sustituyó al mundo geocéntrico -e incluso antropocéntrico-, de la astronomía griega y medieval, por una concepción heliocéntrica que, más tarde, a su vez, sería reemplazada por la conciencia de universo sin centro de la astronomía moderna.

Por otro lado, la implantación masiva del hormigón y el acero como materiales portantes de las construcciones decimonónicas, sustituyendo a los tradicionales muros de carga, invitó a emprender un nuevo rumbo en el diseño de huecos, pues permitía cerrar las fachadas solo con vidrio, originando una atmósfera que des-

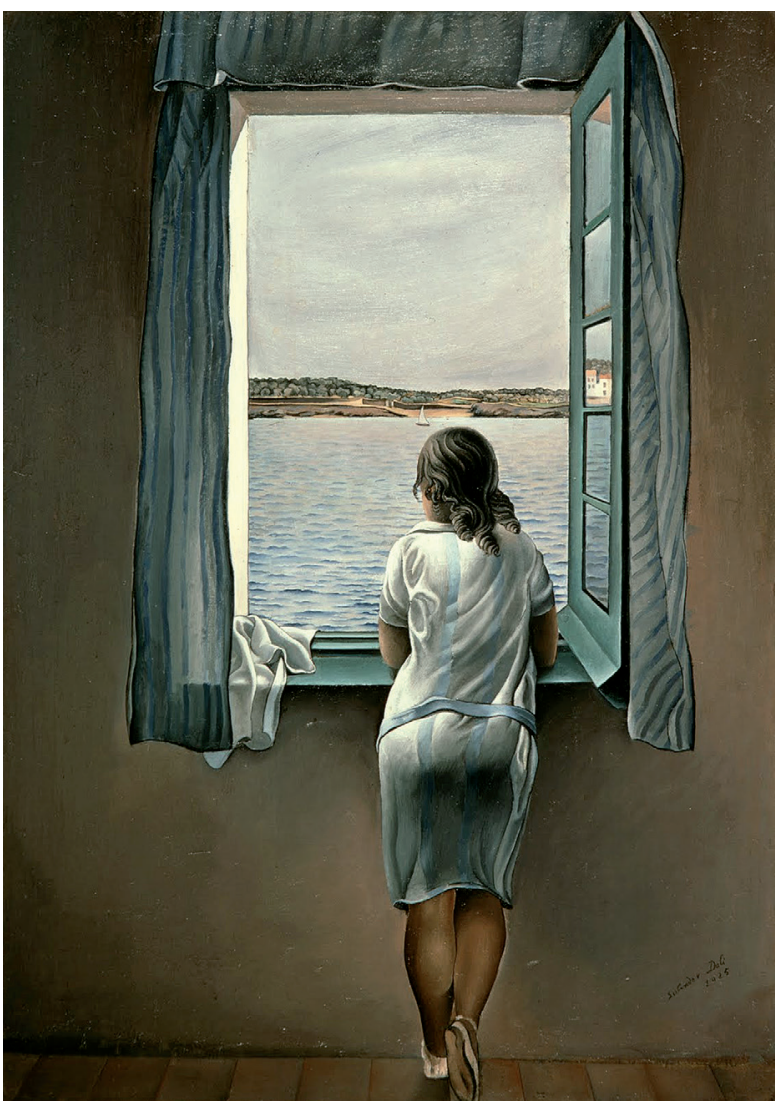

Fig. 5. Salvador Dalí: Figura en una ventana -óleo sobre cartón piedra, 105 x 74,5 cm- (1925).

Fundació Gala-Salvador Dalí, Figueras; Museo Nacional Centro de Arte Reina Sofía, Madrid. comprimía el espacio -sin menoscabo del necesario abrigo a todo tipo de inclemencias--. Un auge tecnológico, rápidamente propagado, que fomentaría una notoria simbiosis con el medio; la idea de espacio interconectado fue gratamente acogida por los integrantes del Movimiento Moderno, adoptando luz, sol y aire como premisas de proyecto, lo que impulsó la proliferación de zonas libres y abiertas. Aparte de por cuestiones funcionales, preferentemente higiénico-sanitarias, ello se debió a la conciencia espacio-temporal de dicha generación y que, según Sigfried Giedion, inducía a dotar de una cualidad específica a los edificios en cuanto a su transparencia, de tal forma que permitieran observar su interior y exterior simultáneamente, al igual que sucede en numerosas pinturas cubistas, donde aparecen representadas, de manera conjunta, dos visiones de una misma figura ${ }^{33}$.

${ }^{32}$ Benevolo, 1994: 9. La cita se corresponde con el párrafo con que arranca el prefacio, en el que también se incluye una remisión, en el plano científico, a KoYRE, 2000.

${ }^{33}$ Véanse Giedion, 1975; 2009. A modo de síntesis, cabe consultar lo expuesto en Cachorro, 2013.

Arch. esp. arte, LXXXVIII, 350, ABRIL-JUNIO 2015, 157-172

ISSN: 0004-0428, eISSN: 1988-8511, doi: 10.3989/aearte.2015.10 


\section{Ilusión}

El también surrealista René Magritte se inclinó por jugar con la contradicción y el engaño, haciéndonos partícipes de un pensamiento complejo, manejando ideas altamente filosóficas y no menos poéticas. En su serie La condition humaine (La condición humana, 1933-1935), fusiona figura y fondo; en la primera de estas obras nos enseña un caballete delante de una ventana, haciendo que la tela que sustenta se mimetice con el paisaje, en perfecta sintonía con los postulados de Alberti y con alusión directa a la 'ventana de Leonardo' -que permite dibujar situando un vidrio entre el artista y el modelo-, lo que hace suponer que la representación constituye una reproducción fiel de la realidad, aunque sin poder confirmarlo; en una de las cartas remitidas por el pintor belga a su amigo André Breton, en 1934, le explicaba que lo esencial en esta creación era eliminar la diferencia entre lo que se ve desde fuera y desde dentro ${ }^{34}$. En continuidad con lo anterior, concebiría La clef des champs (La llave del campo, 1936) -expresión francesa que sugiere despojo de cualquier restricción mental o física-, donde el cristal de una ventana cae al suelo, roto en pedazos, arrastrando consigo los trozos de imagen que cada uno mostraba, evidenciando que tan solo era una estampa superpuesta, un cuadro en el propio hueco que, a pesar de ser coincidente con el exterior, nos hace replantear la condición veraz o ficticia de nuestra percepción. Más si cabe cuando, en ambos trabajos, se añade una componente teatral, dibujando un cortinaje perimetral a modo de telón.

Décadas más tarde, en La lunette d'approche (El telescopio, 1963), Magritte conseguirá, apelando al absurdo, que las dos hojas de una ventana manifiesten plena incongruencia; mientras que una permite contemplar el cielo con absoluta normalidad, la otra niega tal circunstancia para delatar, en verdad, que detrás de ellas no existe nada, si acaso el vacío, que se trata únicamente de una pura apariencia. Así, plantea una reflexión acerca de la ventana que, más allá de aludir a la noción renacentista de perspectiva, intenta profundizar en la correspondencia entre lo que vemos y lo que realmente es; se podría decir que poniendo en duda la «veritas» que aportan nuestras retinas, según la definición de Santo Tomás - como «adaequatio rei et intellectus» ${ }^{35}$.

Una consideración a la que acude Ortega y Gasset, también de manera metafórica, para ilustrar en qué consiste, a su criterio, el arte. Igualmente, diferenciaba el plano del cristal de una ventana (que personifica la obra artística) de la indefectible realidad que aparece tras de sí, con la que podía -o debía, según las nuevas tendencias- no coincidir: lo retratado y su retrato son dos objetos totalmente distintos; para gozar a nivel plástico, este último debe ser una imagen irreal, una ficción. En palabras del pensador madrileño: “...estamos mirando un jardín a través del vidrio de una ventana. Nuestros ojos se acomodarán de suerte que el rayo de la visión penetre el vidrio, sin detenerse en él, y vaya a prenderse en las flores y frondas. [...] Cuanto más puro sea el cristal menos lo veremos. Pero luego, haciendo un esfuerzo, podemos desentendernos del jardín y, retrayendo el rayo ocular, detenerlo en el vidrio. Entonces el jardín desaparece a nuestros ojos y de él solo vemos unas masas de color confusas que parecen pegadas al cristal. Por tanto, ver el jardín y el vidrio, son dos operaciones incompatibles: la una excluye a la otra y requieren acomodaciones oculares diferentes. [...] la mayoría de la gente es incapaz de acomodar su atención al vidrio y transparencia que es la obra de arte; en vez de esto, pasa a través de ella sin fijarse y va a revolcarse apasionadamente en la realidad humana que en la obra está aludida"36.

\footnotetext{
34 Véase Pierre, 1998.

${ }^{35}$ Como antecedente lejano de los contrasentidos visuales encontramos la afición barroca por los trampantojos y las situaciones contradictorias de mutua exclusión; entre ellas cabe destacar, por ejemplo, la que Murillo plantea en su $\mathrm{Au}$ torretrato (h. 1670) -calificada como 'fricción de contrarios' según el análisis expuesto en Gallego Serrano, $1984: 186$.

${ }^{36}$ Ortega y Gasset, 1987: 50-51.
} 


\section{Soledad}

La vinculación de De Chirico con la arquitectura resulta obvia, reflejada ya en su pintura metafísica previa a la I Guerra Mundial, mediante innumerables espacios urbanos con entornos construidos, donde sobresalen arcos junto a puertas y ventanas de carácter esquemático, con fondo oscuro y sombrío - supuestamente cerradas o clausuradas, como en señal de luto-, cuya opacidad exterior insinúa lugares inhabitables, extraños e inexplicables, reforzando un hondo y emotivo sentimiento de vacío, tristeza y alienación del mundo, ya definido por el resto de la ambientación, donde la ausencia de personas - a veces sustituidas por la frialdad de siluetas o autómatas como también hizo, por ejemplo, Georg Grosz- subraya la conciencia de pérdida y decadencia, el arrinconamiento y desamparo del hombre moderno en un mundo enajenado ${ }^{37}$.

En otra singular atmósfera, a pesar de su lenguaje totalmente distinto, de corte realista, Edward Hopper recrea sencillas y cotidianas escenografías edificadas que giran alrededor de grandes vanos, aparentemente desprovistos de cristal, que permiten una mejor percepción del entorno y favorecen la dialéctica entre dentro y fuera. Muestran un deliberado carácter abstracto, donde la luz inunda las habitaciones, tensando el espacio. En este peculiar y sugerente marco se nos presentan sujetos en actitud de espera, que activan su mirada para tornarse meditabundos, contagiando de su intensa reflexión al propio espectador, tal como ocurre en Morning sun (Sol de mañana, 1952), Hotel by a railroad (Hotel junto al ferrocarril, 1952) y Office in a small city (Oficina en una pequeña ciudad, 1953), ${ }^{38}$ donde melancolía y, sobre todo, conducta solitaria -en cierto modo autista- se imponen como rasgos característicos del fenómeno ciudadano contemporáneo, suscribiendo el mismo estado de ánimo que indujo a Miguel Hernández a recitar: "Mis ojos, sin tus ojos, no son ojos, / que son dos hormigueros solitarios, / ..."39. Un aislamiento en el que, llamativamente, aunque tomado con distinto sentido, también incurrió Hopper por cuanto, al igual que otros grandes maestros, su personalidad y estilo configuraron un perfil tan excepcional que da pie a individualizarlo dentro del panorama artístico del momento.

En todo caso, esta sensación, nacida de la paleta del estadounidense, habría que entenderla más bien de incomunicación; cualidad que, de manera paradójica, dista mucho del potencial semántico y de la infinidad de mensajes que nos puede transmitir un elemento tan sencillo, inmaterial, como una ventana, generador de un abanico ilimitado de posibilidades tanto de relación como de revelación.

\section{Conclusiones}

La tradición pictórica, longeva en recurrir a la ventana como género artístico, nos muestra su rica aportación espacial, en profundidad o perspectiva, logrando un siempre atractivo diálogo entre interior y exterior, acorde con el carácter entreabierto que se atribuye al ser humano, en búsqueda constante de un equilibrio entre lo agorafóbico y lo claustrofóbico; a lo que se añade el extraor-

\footnotetext{
${ }^{37}$ El greco-italiano había meditado sobre el fenómeno de la ausencia humana en el sentido metafísico, distinguiendo dos tipos de soledad en las obras de arte profundas: la «soledad plástica» o placer contemplativo que da la genial construcción y combinación de las formas; y la «soledad de los signos», eminentemente espectral, en tanto que surge del deseo de objetivar el mundo, de revelar la esencia de las cosas, despojando lo originario o consustancial (eterno) de todo cuanto es original o accesorio (transitorio) hasta quedar como fragmentos sueltos, aislados de un presente cambiante, ajenos al orden que habitualmente se les impone (De Chirico, 1990: 42).

${ }^{38}$ Véase Hidalgo, 2008, donde el autor intenta descifrar las historias que ocultan las obras de Hopper desde su condición de guionista cinematográfico; así como Llorens; Ottinger, 2012.

39 Hernández, 1999: 127, como encabezamiento del soneto II de "Imagen de tu huella" (1934).
}

Arch. esp. arte, LXXXVIII, 350, ABRIL-JUNIO 2015, 157-172

ISSN: 0004-0428, eISSN: 1988-8511, doi: 10.3989/aearte.2015.10 


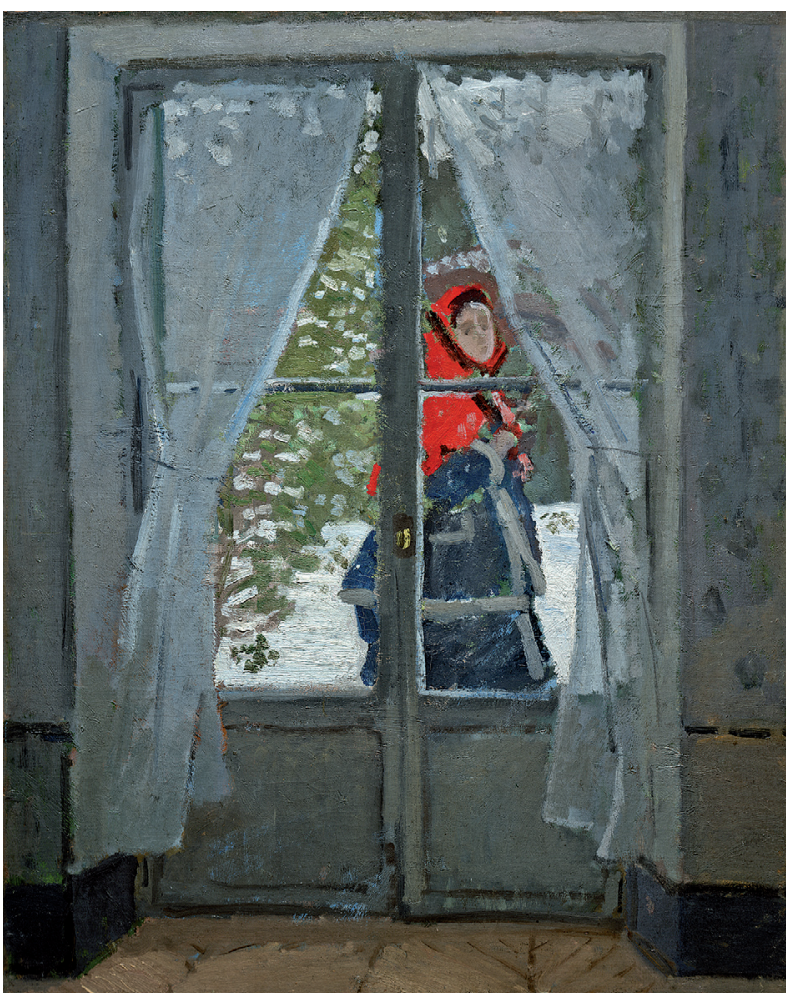

Fig. 6. Claude Monet: La capeline rouge (El pañuelo rojo) -óleo sobre tela, 128,27 x 105,73 x 14,6 cm-

(h. 1868-1873). The Cleveland Museum of Art, legado de Leonard C. Hanna, Jr. 1958.39. dinario interés despertado por su capacidad evocadora o metafórica, ejercida mediante el encuadre visual y la excitación contemplativa a partir de situaciones y registros de muy variada índole.

Se trata, pues, de una cuestión de fondo, de mucho mayor alcance a lo puramente formal, donde la fenomenología de mirar surge como indicio, como rasgo delator de discursos que pueden identificar toda una doctrina que, de manera sólida, subyace detrás de este elemento, más allá de su contribución estética y funcional. Y es que, de una u otra manera, los edificios, a través de sus poros, siempre hablan.

Un fragmento de vacío cuya sola presencia continúa cautivando con su asombrosa capacidad de seducción ${ }^{40}$. Prosaico pero a la vez grandioso, convertido en auténtico símbolo arquitectónico, cuya significación traspasa con amplitud el ámbito físico para reafirmarse como origen de los más hondos sentimientos, estimulando lo que Jacques Lacan denominó «pulsión escópica» o esquizia del ojo, un deseo irrefrenable de mirar -con el que también asociaba las sensaciones de pudor, miedo...- ${ }^{41}$. Voyeurismo que fue captado a la perfección en la narrativa de Fernando Pessoa: "Ao entardecer eu fiava, sentada à minha janela. A janela

dava para o mar e às vezes havia uma ilha ao longe... Muitas vezes eu não fiava; olhava para o mar e esquecia-me de viver" ${ }^{2}$; y cuyo sublime efecto ha quedado igualmente recogido por Rainer Maria Rilke en sus elocuentes versos: "N'es-tu pas notre géométrie, / fenêtre, très simple forme / qui sans effort circonscris / notre vie énorme? / Celle qu'on aime n'est jamais plus belle / que lorsqu'on la voit apparaître / encadrée de toi ; c'est, ô fenêtre, / que tu la rends presque éternelle. / ..."43 (fig. 6).

${ }^{40}$ Entre otros textos, véanse Delehanty; Blum, 1986. Friedberg, 2006. Müller-Schareck; Vietmeier, 2012. Franciolli; Iovane; Würmann, 2013. Soria, 2000.

${ }^{41}$ Véase Lacan, 1987. A las pulsiones freudianas ya investigadas del individuo, el autor del texto añade otras dos: la escópica y la invocante, asociadas a la mirada y a la voz respectivamente.

${ }^{42}$ Tr.: Al atardecer, hilaba sentada a mi ventana. La ventana daba al mar y a veces había una isla a lo lejos... Muchas veces no hilaba: miraba al mar y se me olvidaba vivir -Pessoa, "El marinero. Drama estático en un cuadro (1913)", 2009: 364.

${ }^{43}$ Tr.: “¿No eres nuestra geometría en verdad, / ventana, forma muy simplificada / que circunscribes sin dificultad / nuestra vida desmesurada? / Nunca la amada más bella ha estado / que cuando la vemos aparecer allí / oh ventana, enmarcada por ti; / y es que en eterna casi la has transformado. / ..."-Rilke, "Vergers / Vergeles", 1994: 50, I, 76-77 (y 153-154, donde se repite como parte de "Fenêtres", III).

Arch. esp. arte, LXXXVIII, 350, ABRIL-JUNIO 2015, 157-172 ISSN: 0004-0428, eISSN: 1988-8511, doi: 10.3989/aearte.2015.10 


\section{BIBLIOGRAFÍA}

Baudelaire, Charles (2009): El spleen de París. Pequeños poemas en prosa, M. Neila (ed.), Sevilla: Espuela de Plata, (ed. original de 1862).

Benevolo, Leonardo (1994): La captura del infinito, Madrid: Celeste, (ed. original de 1991).

Berman, Marshall (1991): "Baudelaire: el modernismo en la calle". En: Todo lo sólido se desvanece en el aire. La experiencia de la modernidad, Madrid: Siglo XXI.

Blum, Shirley Neilsen (2010): Henri Matisse. Rooms with a view, Londres: Thames and Hudson.

Bozal, Valeriano (2002): Johannes Vermeer de Delft, Madrid, TF.

Cachorro, Emilio (2013): “Anhelos de continuidad espacial”. En Calatrava, Juan (ed.), La arquitectura y el tiempo. Patrimonio, memoria, contemporaneidad, Madrid: Abada, pp. 389-402.

Calatrava, Juan (1996): "Poeta y ciudad: Baudelaire «Pintor de la vida moderna»". En Sileno, 1, Madrid: Abada.

Cavafis, Constantino (2000): “Poemas canónicos (1895-1915)”, Antología poética, P. Bádenas (ed.), Madrid: Alianza.

Cortázar, Julio (1963): Rayuela, Buenos Aires, Sudamericana.

De Chirico, Giorgio (1990): Sobre el arte metafísico y otros escritos, Murcia: COAATM; Librería Yerba.

Dalí, Ana María (1949): Salvador Dalí, visto por su hermana Ana María, Barcelona: Juventud.

De Vinci, Leonardo; Alberti, Leon Bautista (1980): El Tratado de la Pintura por Leonardo de Vinci y los tres libros de la pintura que sobre el mismo arte escribió Leon Bautista Alberti, Murcia: COAATM; Librería Yerba.

Delehanty, Suzanne / Blum, Shirley Neilsen (ed.) (1986): The window in twentieth-century art, cat. exp., Nueva York: Neuberger Museum of Art.

Dumont, Marie-Jeanne (ed.) (2002): Le Corbusier. Lettres à Auguste Perret, París: Linteau.

Durand, Gilbert (1982): Las estructuras antropológicas de lo imaginario, Madrid: Taurus.

Eitner, Lorenz (1955): "The open window and the storm-tossed boat: an essay in the iconography of Romanticism". En: The Art Bulletin, 37, 4, diciembre, pp. 281-290.

Filgueira Valverde, José (1974): Con Rosalía de Castro en su hogar / Con Rosalía de Castro no seu fogar, Vigo: Patronato Rosalía de Castro.

Forssman, Erik (1966): "Fensterbilder von der Romantik bis zur Moderne”. En: Konsthistoriska studier tillagnäde Sten Karling, Estocolmo: Kungliga Universitetet, pp. 289-320.

Forster, Edward Morgan (2005): Una habitación con vistas, Madrid: Alianza (ed. original de 1908).

Franciolli, Marco; Iovane, Giovanni; Würmann, Sylvie (comisarios) (2013): Una finestra sul mondo. Da Dürer a Mondrian e oltre: sguardi attraverso la finestra dell'arte dal Quattrocento ad oggi, cat. exp., Milán: Skira.

Frechuret, Maurice / Muller, Markus Joseph / Pacoud-Reme, Elisabeth (coms.) (2008): Chagall, un peintre à la fenetre, cat. exp., París: Réunion des Musées Nationaux.

Friedberg, Anne (2006): The virtual window. From Alberti to Microsoft, Cambridge (MA), The MIT Press.

Gallego Serrano, Julián (1984): El cuadro dentro del cuadro, Madrid: Cátedra.

Giedion, Sigfried (1975): La arquitectura fenómeno de transición. Las tres edades del espacio en arquitectura, Barcelona: Gustavo Gili (ed. original de 1971).

Giedion, Sigfried (2009): Espacio, tiempo y arquitectura. Origen y desarrollo de una nueva tradición, Barcelona: Reverté (ed. original de 1941).

González Besada (1916): Augusto, Rosalía de Castro. Notas biográficas, Madrid: Biblioteca Hispánica.

Haro Tecglen, Eduardo (ed.) (2000): Lope de Vega, Barcelona, Omega.

Hernández, Miguel (1999): Antología poética, Madrid, EDAF.

Hidalgo, Manuel (2008): "Edward Hopper. Ventanas de América”. En: Descubrir el Arte, 110, Madrid: Arlanza, abril.

Koyre, Alexandre (2000): Del mundo cerrado al universo infinito, Madrid, Siglo XXI (ed. original de 1957).

Lacan, Jacques (1987): El seminario. Libro 11: Los cuatro conceptos fundamentales del psicoanálisis, Barcelona, Paidós (dictado en 1964).

Llorens, Tomás; Ottinger, Didier (coms.) (2012): Hopper, cat. exp., Madrid: Museo Thyssen-Bornemisza. Martín Gaite, Carmen (1958): Entre visillos, Barcelona: Destino.

Arch. esp. arte, LXXXVIII, 350, ABRIL-JUNIO 2015, 157-172

ISSN: 0004-0428, eISSN: 1988-8511, doi: 10.3989/aearte.2015.10 
Martín Gaite, Carmen (1987): Desde la ventana, Madrid: Espasa Calpe.

Martín Gaite, Carmen (2001): "Por el mundo adelante". En: Después de todo. Poesía a rachas, Madrid, Hiperión.

Müller-Schareck, Maria / Vietmeier, Melanie (coms.) (2012): Fresh Widow. The window in art since Matisse and Duchamp, cat. exp., Düsseldorf: Kunstsammlung Nordrhein-Westfalen.

Nufrio, Anna (ed.) (2008): Eduardo Souto de Moura. Conversaciones con estudiantes, Barcelona: Gustavo Gili.

Ocaña, María Teresa (ed.) (1999): Picasso: paisaje interior y exterior, cat. exp., Barcelona, Institut de Cultura de Barcelona y Museu Picasso.

Ortega y Gasset, José (1987): “Arte artístico”. En: La deshumanización del arte y otros ensayos de estética, Madrid, Espasa Calpe, pp. 49-54 (ed. original de 1925).

Panofsky, Erwin (1999): La perspectiva como forma simbólica, Barcelona: Tusquets (ed. original de 1927).

Pessoa, Fernando (2009): Antología poética. El poeta es un fingidor, Crespo, A. (ed.), Madrid, Espasa Calpe.

Pierre, José (1998): "Magritte: la ventana en la ventana”. En: Borràs, Maria Lluïsa (comisaria), Magritte, cat. exp., Barcelona, Fundació Joan Miró.

Rewald, Sabine (com.) (2011): Rooms with a view. The open window in the 19th century, cat. exp., Nueva York: The Metropolitan Museum of Art.

Rilke, Rainer Maria (1994): Poemas franceses, T. Segovia (ed.), Valencia, Pre-Textos.

Robles Tardío, Rocío (2008): “Censando el mundo desde las ventanas de los vagones”. En: Pintura de humo. Trenes y estaciones en los orígenes del arte moderno, Madrid: Siruela.

Rosalía de Castro (1993): En las orillas del Sar, Madrid, Akal (ed. original de 1884).

Schmoll, Josef Adolf (Eisenwerth) (1967): "Der blick durch das offene fenster. Ein motiv der malerei des 19. Jahrhunderts". En Kaiser, Konrad (ed.), Der frühe Realismus in Deutschland 1800-1850. Gemälde und zeichnungen aus der sammlung Georg Schäfer, Schweinfurt, cat. exp., Núremberg: Germanisches Nationalmuseum, pp. 132-144.

Schmoll, Josef Adolf (Eisenwerth) (1970): "Fensterbilder. Motivketten in der europäischen malerei”. En: L. Grote (ed.), Beiträge zur motivkunde des 19. Jahrhunderts, Múnich: Prestel, pp. 13-165.

Soria, Martine (ed.) (2000): La ventana en el arte-Leihoa artean, cat. exp., Bilbao: Fundación BBK.

Torre Fica, Iñaki (2001-2002): "La mujer ventanera en la poesía de Carmen Martín Gaite". En: Espéculo. Revista de Estudios Literarios, 19, Madrid: Universidad Complutense.

Van der Laan, Hans (1989): L'espace architectonique: quinze leçons sur la disposition de la demeure humaine, Leiden: E. J. Brill.

Verlaine, Paul (1991): “La buena canción”. En: La buena canción. Romanzas sin palabras. Sensatez, M. Casado (ed.), Madrid: Cátedra, VII (ed. original de 1869).

Zumthor, Peter (2006): Atmósferas, Barcelona: Gustavo Gili.

Fecha de recepción: 19-IX-2013

Fecha de aceptación: 28-I-2014

Arch. esp. arte, LXXXVIII, 350, ABRIL-JUNIO 2015, 157-172 ISSN: 0004-0428, eISSN: 1988-8511, doi: 10.3989/aearte.2015.10 